\title{
A LATI e o projeto estadunidense de controle do mercado de aviação no Brasil ${ }^{*}$
}

\author{
The LATI and the North-American Project \\ to control the Brazilian aviation market
}

\author{
TANIA QUINTANEIRO \\ Departamento de Sociologia e Antropologia da UFMG \\ Mestre em Ciência Política \\ taniaq@terra.com.br
}

\begin{abstract}
RESUMO Um dos principais objetivos da política externa dos Estados Unidos durante a Segunda Guerra foi identificar oportunidades e abrir mercados para investimentos nas repúblicas da América Latina. 0 controle da aviação comercial era estratégico e para alcançar esse objetivo o Departamento de Estado desenvolveu uma ampla campanha contra as empresas em mãos de interesses do Eixo, acusando-as de espionagem e contrabando, e pressionou os governos nacionais para obter sua colaboração. Este artigo examina os efeitos da política estadunidense sobre a LATI, empresa estatal italiana de transporte aéreo que fazia a rota Roma-Brasil, e que ficou sob fogo diplomático entre 1941 e inícios de 1942, quando foi definitivamente expulsa do espaço aéreo brasileiro.
\end{abstract}

\footnotetext{
Artigo recebido em 15/11/2006. Aprovado em 23/01/2007

(Uma bolsa da FAPEMIG possibilitou a pesquisa de fontes primárias nos National Archives and Records Administration (NARA), em Maryland. Para os propósitos dessa pesquisa, a documentação mais relevante é a do Departamento de Estado, que se encontra organizada nos Records of the Foreign Senvice Posts, ou Record Group 84 (RG 84).)
} 
Palavras-chave LATI, Segunda Guerra Mundial, política externa norte-americana

ABSTRACT One of the main goals of the United States foreign policy during World War II was to identify opportunities and open up markets for investment in the Latin American Republics. The control of commercial aviation was crucial and towards that end, the Department of State developed a vast campaign against companies that were in the hands of Axis interests, accusing them of carrying out espionage activities and contraband, and exerting pressure over national governments to obtain their collaboration. This article examines the effects of American policy over LATI, an Italian state airline who flied from Rome to Brazil, which came under diplomatic fire in 1941, until it was finally evicted from the Brazilian air space in 1942.

Key words LATI, World War II, American foreign policy

O controle das empresas de transporte aéreo nas repúblicas sul-americanas foi um dos mais caros objetivos dos Estados Unidos no decorrer da Segunda Guerra, haja vista que, no Brasil, como de resto em outros países da América Latina, parte substancial dessa rede de transporte encontrava-se já desde a década de 20 em mãos de capitais e empresas européias, particularmente alemãs. A estratégia de conquista e ocupação de espaços econômicos promovida pelo Departamento de Estado norteamericano associou fortes pressões políticas e ideológicas à busca de adesão dos governos nacionais, tanto do ponto de vista simbólico como material. Sendo a aeronáutica um setor de tecnologia de ponta em rápida expansão, atraía altos investimentos, estatais e privados. Mais do que isso, a mobilidade aérea correspondia pari passu com o aumento do poderio militar, fazendo da segurança geopolítica um argumento recorrente e eficaz naquela conjuntura. ${ }^{1}$

Para colocar em prática sua política expansionista e, em parte, como conseqüência das próprias exigências da guerra, o Estado norte-americano promoveu uma racionalização da sua burocracia, criou novas agências, ampliou outras já existentes e articulou-as com interesses privados. Além disso, mobilizou especialistas de diversas áreas, incorporou alguns deles a seus quadros permanentes, deslocou-os para os órgãos onde eram necessários,

1 Sobre a mudança de postura da administração Roosevelt com relação ao tradicional isolacionismo dos Estados Unidos, ver HAGLUND, David G. Latin America and the transformation of U. S. strategic thought - 1936-1940. Albuquerque: University of New Mexico Press, 1984. 
ou enviou-os às repúblicas vizinhas de modo a construir uma base de apoio para as decisões de sua política externa. Devido à qualidade e precisão dos documentos gerados por funcionários e consultores, é possível retraçar as manobras então adotadas, cuja finalidade era alcançar e consolidar a hegemonia dos Estados Unidos no continente, em circunstâncias políticas locais mais ou menos favoráveis.

No início da Segunda Guerra, operavam no Brasil duas empresas de transporte aéreo vinculadas a investimentos de países do Eixo: a Condor Syndikat e a Linee Aeree Transcontinentali Italiane ou LATI. A primeira, subsidiária da alemã Lufthansa, atuava também em outros países da América Latina e se estabelecera no Brasil em 1927, tendo sido nacionalizada no mesmo ano em atendimento a exigências da Constituição brasileira. A Condor mantinha uma extensa malha aérea no Brasil, por meio da qual uma grande parte da América do Sul se encontrava estreitamente conectada. Voava no Chile, na Argentina, na Bolívia, onde tinha contratos com o Lloyd Aereo Boliviano, propriedade de imigrantes alemães, no Peru, onde pousavam aviões da Lufthansa, e em outros países; e continuava em expansão. A segunda delas era subsidiária da estatal Ala Littoria, que desde 1934 ligava a Itália às suas colônias na África e a outros países europeus. A LATI fora fundada por Mussolini em 11 de setembro de 1939. 0 que a distinguia era ser a única ligação aérea direta entre o Brasil e a Europa. No transporte de passageiros, carga e correspondência, inclusive malas diplomáticas, utilizava trimotores e quadrimotores rápidos que requeriam pistas extensas. Sua existência era uma prova, aos olhos do governo dos Estados Unidos, de que a Itália tinha propósitos de espionagem e contrabando de materiais de uso bélico. Daí a idéia de colocar "observadores" brasileiros nos aviões para que denunciassem atrasos inexplicáveis ou manobras suspeitas. ${ }^{2}$

A análise da trajetória da LATI no Brasil, durante o curto lapso entre 1941 e 1942, torna inteligível a ação concertada do aparelho de Estado norte-americano para atender às novas necessidades e oportunidades que afloraram com a guerra, e a maneira como implementou uma política externa expansionista na América Latina.

Em 1941, a LATI operava um vôo semanal que saía de Roma, fazia escala na ilha do Sal, arquipélago de Cabo Verde, em seguida aterrissava no Recife e no Rio de J aneiro. Em agosto, seus serviços se estenderam a Buenos Aires onde, assim como no Brasil, havia grandes colônias de imigrantes italianos bem integradas às comunidades locais. A notável ascensão social de algumas famílias de migrantes refletia-se em um mercado promissor para o transporte aéreo intercontinental que a política externa estadunidense procurava abrir para os investimentos de seus capitalistas.

2 O'SHAUGHNESSY, E. 12-8-1941. RG 84, v. XXIX. 
Nesse ano, a companhia estatal italiana foi duramente golpeada pelo governo dos Estados Unidos, até sua completa paralisação. Obter peças de reposição tornou-se difícil e, logo, o acesso ao combustível lhe foi vetado. Seu destino foi semelhante ao de um sem número de companhias e estabelecimentos cujo capital pertencia majoritariamente a empresários que mantinham conexões comerciais ou financeiras com países do Eixo ou estatais dessa origem, ou que fossem naturais daqueles países. Estabelecidas nas repúblicas da América cujos governos apoiaram as forças Aliadas, tais empresas viram-se enredadas nos interesses estadunidenses.

A movimentação das companhias de transporte aéreo de capital originário do Eixo que atuavam nas repúblicas sul-americanas era vigiada por órgãos do Estado norte-americano. No caso da LATI, relatórios detalhados informavam sobre seus passageiros de nacionalidade alemã e italiana, se eram civis, diplomatas ou militares, e sobre sua carga, em particular se levava mica, cristais de quarto ou diamantes industriais, materiais estratégicos de consumo bélico abundantes no Brasil. O governo dos Estados Unidos fazia esforçava-se para impedir que fossem comercializados ou contrabandeados para os países do Eixo e, enquanto isso não foi possível por meio de tratados, procurou seccionar a via de escoamento mantida pela LATI. Registravam-se as reservas de combustível da companhia (estocado ou adquirido em outros países), as mudanças nos horários de vôo, os equipamentos usados, as peças de reposição adquiridas, e com quem negociava - com base nessa rotina obtinha-se um quadro preciso e periódico do andamento da empresa. O Ministério da Aeronáutica no Brasil também colaborava, prestando contas à Embaixada dos movimentos da companhia, como no mal-humorado informe, incluído em correspondência enviada pelo embaixador norte-americano no Brasil ao Departamento de Estado:

Em violação às nossas leis de neutralidade e sem autorização, a LATI fez um vôo de $7 \mathrm{~h}$ e 15 min [no litoral entre Natal e Recife] sob o pretexto de testar 0 consumo de gasolina de um avião que já tinha sido amplamente testado. A LATI está, pela presente, multada em 20 contos e notificada de que sua autorização para voar no Brasil será cancelada no evento da recorrência. ${ }^{3}$

Como as demandas da guerra vinham impedindo que a Alemanha atendesse aos pedidos de peças de reposição feitos pela LATI, esta se voltou aos representantes, no Brasil, de fábricas norte-americanas, a fim de obter pelo menos dezoito grandes motores de avião de que necessitava com urgência. ${ }^{4}$ Comentava-se que estaria disposta a pagar praticamente

CAFFERY 10-4-1941. RG 84, v. XXXVIII.

BURDETT 31-1-1941. Italian airline endeavoring to purchase American airplane engines. RG 84, v. XXXVIII. 
qualquer preço por eles. Mas tais pedidos não teriam resposta daquelas indústrias, já alertadas pelo governo estadunidense, que atribuía o frenesi da companhia italiana a seus propósitos militares. O cerco dos Estados Unidos se completaria com a restrição dos suprimentos de gasolina e óleo à LATI, comercializados por distribuidoras daquele país. Estas foram proibidas, por determinação expressa do Secretário de Estado, Hull, de fornecer à LATI gasolina de aviação para perío do superior a 30 dias. ${ }^{5} \mathrm{O}$ embaixador britânico no Rio fora o inspirador da idéia. ${ }^{6}$

Entretanto, de uma perspectiva mais ampla, o fator decisivo no episódio seria a exclusividade mantida pela empresa italiana na prestação de serviços aéreos entre o Brasil e a Europa, essencial para o serviço diplomático brasileiro. Por isso, sabia-se que o ministro Oswaldo Aranha não autorizaria suspender sua operação sob risco de romper as comunicações entre seu governo e as missões, ${ }^{7}$ o que garantia à LATI condições favoráveis para negociar, caso os norte-americanos apertassem o bloqueio, cortando de vez os combustíveis.

A expulsão da LATI da América do Sul articulava-se ao programa estadunidense de "desgermanização" das empresas de aviação. A solução exigia negociação tanto com as forças políticas locais quanto com a Pan American Airways Inc. a qual, como explicita Burden, especialista da Defense Supplies Corporation (DSC), "embora seja uma companhia privada, é o instrumento da política de aviação dos Estados Unidos no Brasil, e a única companhia norte-americana preparada para inaugurar imediatamente serviços transatlânticos entre o Brasil e a Europa". ${ }^{9}$ Poressa razão, recomendava que o Departamento de Estado, como responsável pelas relações entre os governos, elaborasse um plano ajustado com a Pan Am.

A indicação geral da política norte-americana de "desgermanização" era de que se obtivesse o apoio dos governos nacionais sul-americanos para facilitar ou viabilizar intervenções. Mas enquanto em Washington se esperava que a proibição de que a LATI aterrissasse em pistas brasileiras contasse com o empenho de Vargas, este não parecia "ansioso de fazer tal movimento voluntariamente, como foi o caso da Bolívia". ${ }^{10}$ Para que sua pressão tivesse eficácia, os Estados Unidos deveriam oferecer, além de serviços aéreos substitutos equivalentes, algo que fosse de grande importância para o Brasil - o que as agências encarregadas dessa ne-

\footnotetext{
HULL 2-5-1941. RG 84, v. XXXVIII.

CAFFERY 18-2-1941. Operations of the LATI between Brazil and Europe. Memorandum of conversation Mr. Helm British Embassy. RG 84, v. XXXVIII.

7 CAFFERY 9-5-1941. RG 84, v. XXXVIII.

8 A DSC era uma seção da Division of American Republics Aviation, da Reconstruction Financial Corporation (RFC).

9 BURDEN 14-8-1941. Analysis of possible methods of eliminating Axis influence in Brazilian aviation. RG 84, v. XXXVIII.

10 BURDEN 14-8-1941.
} 
gociação chamavam de "munição não-aeronáutica". Embora a indústria norte-americana fosse capaz, pelo menos em médio prazo, de oferecer serviços substitutivos por meio da Pan Am, não era possível ignorar o que um especialista em política de aviação estadunidense considerava serem os fortes sentimentos nacionalistas dos brasileiros representados por "sua conexão direta com a Europa". ${ }^{11}$ Apoiado em informações confiáveis ou em meras suposições, um consultor da DSC sugeria que Vargas preferiria mover-se indiretamente contra a LATI, enquanto esperava que o governo ou as companhias privadas dos Estados Unidos tomassem a iniciativa em questões tais como a restrição de gasolina ou a oferta de concorrência.

Nesse ínterim, chegou à embaixada no Rio de J aneiro um comitê indicado pela Câmara norte-americana para avaliar, nos países aonde se dirigia o correio aéreo, a segurança, a adequação e suficiência das aeronaves e aeroportos, o treinamento e competência do pessoal e das tripulações de vôo que as operariam, o auxílio de navegação aérea, incluindo serviços de rádio e de clima, e todos os outros fatores que teriam um efeito direto e definitivo sobre riscos. Havia a expectativa, para os próximos anos, de um considerável aumento no número de cidadãos dos Estados Unidos que voariam para a América do Sul. A presença do comitê era também expressão do grande interesse nas perspectivas de crescimento do mercado que poderiam se materializar com o término da guerra, quando os Estados Unidos voltassem seus recursos militares à construção de aviões de transporte civil, não apenas para linhas domésticas, mas para o serviço transcontinental e transoceânico. 0 desenvolvimento tecnológico do setor, estimulado pelo conflito bélico, e a disponibilidade industrial e de capital que se podia antever quando aviões de combate fossem menos necessários, tornavam diagnósticos dessa natureza estratégicos para a implantação e consolidação da hegemonia dos Estados Unidos. Em relação à LATI, a queixa da comissão foi de que, por motivos que julgava "obviamente militares", seus horários não eram anunciados com antecedência, sendo a linha de extrema periculosidade em razão de

levar representantes e correspondência do Eixo em ambas as direções, e no transporte, no Brasil, de materiais altamente valiosos de pequeno volume. Do Brasil: diamantes, outras pedras preciosas, cristais de quartzo. Da Europa, a carga consiste de cartas de propaganda, e os passageiros: oficiais italianos e alemães. De fato, a principal função desta linha é levar correspondência para e desde as embaixadas alemã e italiana na América do Sul. Tem sido o meio

11 O'SHAUGHNESSY 1-10-1941. RG 84, v. XXXVIII. 
pelo qual a propaganda do Eixo tem sido transportada e distribuída na América do Sul. ${ }^{12}$

Além de ser considerada pelos Aliados um meio para propaganda, estes suspeitavam de que a companhia estatal italiana proporcionasse informação a seu governo sobre o movimento dos barcos britânicos, já que atravessava importantes rotas marítimas. Deveria ser eliminada o mais rapidamente possível e, simultaneamente, oferecido um atend imento equivalente substituto, o que requereria grandes aviões e financiamento da Federal Loan Agency. ${ }^{13}$ O Departamento de Estado vinha pressionando a RFC para que fechasse um acordo com a Pan Am a fim de que esta iniciasse um vôo semanal com grandes aviões entre New York, Belém, Natal, África O cidental Portuguesa e Lisboa. Esta decisão não só custaria caro como implicaria em redução de outros financiamentos, e o governo dos Estados Unidos tinha, para isso, que se assegurar de que a principal concorrente da Pan Am no Brasil, a LATI, fosse posta fora de combate. Essa era,

de fato, a única razão para o estabelecimento do novo serviço, que pode ser iniciado com um avião dentro de 60 dias e com dois aviões no fim de 90 dias ou possivelmente um pouco mais cedo. Um serviço quinzenal pode ser estabelecido por um avião e um serviço semanal por dois aviões. A Pan Am também conseguirá DC 3 adicionais entre Natal e Buenos Aires, substituindo as rotas da LATI entre os dois pontos. ${ }^{14}$

Funcionários do Departamento de Estado pensavam discutir o assunto com a Pan Am "antes de mencionar isso aos brasileiros". Se a Pan Am não se dispusesse a assumir a rota, era o caso de insistir para que o fizesse a Panair do Brasil, sua subsidiária, se fosse esse "o único modo de ficarmos livres da LATI". ${ }^{15} \mathrm{E}$, como forma de escapar a meandros legais, havia uma terceira opção: registrar em outro país, como o Panamá, um avião operado pela Pan Am. Caso se decidisse pela rota Rio-Lisboa, seria solicitado à DSC que reservasse fundos para a compra de equipamento transoceânico para a Pan Am, em lugar dos subsídios públicos que não podiam ser concedidos pelo correio estadunidense. A última alternativa era que o vôo a Lisboa fosse quinzenal, tendo New York como base, e criando uma conexão direta, há

12 COMMITTEE of the HOUSE of REPRESENTATIVES 16-10-1941. . Summary Report on Air Activity in Brazil and South America. Strictly Confidential Files, box 6.

13 BURDEN 14-8-1941. Devido às provisões do Ato de Neutralidade, não eram concedidos direitos de aterrissagem e registro para aviões comerciais dos Estados Unidos nas duas possessões britânicas na costa ocidental da África (Serra Leoa e Gâmbia Britânica). Entretanto, a operação de um serviço comercial por um avião do exército estadunidense era indesejável. A Pan Am vinha aterrissando em Bolama, na Guiné portuguesa, mas esse direito estava por expirar e, em vista do grau de influência alemã em Portugal, Burden não acreditava que fosse renovado.

14 DEPARTMENT Of STATE 13-10-1941. RG 84, v. XXXVIII.

15 DEPARTMENT Of STATE 18-8-1941. RG 84, V. XXXVIII. 
tempos desejada, entre os Estados Unidos e o Rio de J aneiro, a qual poderia contar com os subsídios dos correios estadunidenses para se viabilizar.

Burden apresentou a funcionários do alto escalão ${ }^{16}$ do Estado norte-americano uma análise complexa, com diversas recomendações que visavam a solucionar os problemas relacionados à presença do Eixo no espaço aéreo brasileiro. De uma perspectiva ampla, assegurava que "o programa de aviação deve se tornar um ponto cardinal da política dos Estados Unidos no Brasil". O Departamento de Estado deveria dedicarse a angariar o apoio de outras agências governamentais e a avaliar que tipo ou quantidade de concessões estava disposto a oferecer ao Brasil. Apesar de todos os recursos que lhe fossem disponibilizados para isso, aeronáuticos ou não, a implantação do programa seria um trabalho árduo, sendo indispensável a disposição a pressionar ativamente o governo brasileiro. Em caso contrário, recomendava adiá-lo. Três planos foram citados no documento: um esquema paralelo da Pan Am, de fevereiro de 1941, a proposta da Pan Am para a nacionalização da Panair do Brasil, de abril de 1941, e o projeto conjunto, de julho de 1941, do próprio Burden e de Russell, da Federal Loan Administration, que tinha sido amplamente debatido com autoridades brasileiras.

Os Departamentos de Estado e de Correios convocaram então a RFC, a Pan Am e o Civil Aeronautics Board para discutir a proposta e elaborar 0 plano definitivo com o qual cada agência viesse a se comprometer de fato. A ação dos participantes deveria ser coordenada, de modo a garantir coerência estratégica. Essa capacidade de atuar em rede era uma vantagem que o Estado norte-americano vinha explorando com crescente eficiência, de forma que, em geral, as políticas públicas contavam, tanto na produção quanto no cumprimento, com a participação dos interesses envolvidos, incluindo os privados. Propôs-se então que um serviço equivalente ao da LATI fosse imediatamente fornecido pelo capital privado (pela Pan Am ou eventualmente pela Panair). 0 benefício mais amplo a ser obtido, caso a ação fosse bem-sucedida, era a proteção de direitos futuros dos Estados Unidos no Atlântico sul. Para assegurar o empenho da Pan Am em operar a rota, era necessário definir de que fonte seriam obtidos subsídios legais, sem desconsiderar o apelo simbólico que poderia ter, para o governo brasileiro, a operação transatlântica através da Panair. ${ }^{17}$ Subsistia a dúvida se 0 Brasil estaria disposto a tomar medidas mais drásticas contra as empresas visadas, mas nada impedia que a possibilidade fosse explorada. A eliminação da LATI, especificamente, não tinha sido ainda objeto de planos tão

16 Eram: Adolf Berle J r., Assistente de Secretário de Estado, Laurence Duggan, Conselheiro de Relações Políticas da Divisão das Repúblicas Americanas, Philip Bonsal, Chefe da Divisão das Repúblicas Americanas, Thomas Burke, Chefe da Divisão de Comunicações Internacionais, e um consultor de aviação.

17 RUSSELL; BURDEN 21-7-1941. Plan presented to Brazilian government. Enclosure to dispatch 14-8-1941. RG 84, V. XXXVIII 
detalhados quanto os que já se dedicavam à rede "germânica" de transporte aéreo atuante na América.

Para abater a LATI, o primeiro passo foi o corte da gasolina. Os Estados Unidos informariam à Standard Oil do Brasil e ao governo brasileiro que não mais permitiriam a importação de gasolina para a companhia italiana, e que tratariam de se assegurar de que o combustivel não lhe chegaria por outras fontes. Entretanto, a LATI tinha reservas para ao menos quatro meses e, para que elas se exaurissem, era preciso impedir vazamentos no esquema, sendo a Standard proibida de fazer entregas adicionais, mesmo em emergências, ${ }^{18}$ e de transferir os estoques da LATI, de Natal para outros pontos onde eram necessários, agravando as dificuldades. 0 tempo era a essência dessa campanha de asfixia. Na medida em que a LATI que não tinha contrato assinado com a Standard, não havia como impetrar um processo contra esta, como fizera a Condor.

Com base em um diagnóstico da LATI, a DSC comprou duas aeronaves modelo Transocean Flying Boats da Pan Am, que aceitara operar a rota Brasil-Lisboa. Em 90 dias os serviços poderiam ser iniciados, desde que o governo brasileiro concordasse em cancelar a franquia da LATI nos próximos 60 dias, ou seja, até janeiro de 1942. Além disso, navios rápidos seriam instalados numa rota semanal New York, Porto Rico, Belém, Natal, Bolama, Lisboa. Por fim, uma conexão aérea com aviões fornecidos pela DSC ligaria Buenos Aires ao Rio de J aneiro, Belém ou Natal. ${ }^{19}$ Harding, da DSC, esperava que, dentre os três planos alternativos sugeridos, dois conquistariam o apoio do governo brasileiro. Mas, independentemente de tal aprovação, apostava em que o presidente de seu país proibiria, de fato, 0 fornecimento de combustível, de modo que a situação dos serviços aéreos substitutos poderia se decidida, como sublinhava, "em nossos termos". ${ }^{20}$ Em outras palavras, se a negociação não funcionasse, nada mais eficaz do que a força.

A LATI começou a demonstrar que os suprimentos estavam em rápida baixa quando cessou de operar Recife-Rio de J aneiro, tendo conseguido que a Condor levasse seus passageiros e fretes. ${ }^{21}$ Apesar de ter ameaçado apelar à polícia local para obter a posse da gasolina de aviação, legalmente pertencente a ela e estocada no armazém da Standard Oil, a embaixada estava segura de que nem assim iria consegui-la. ${ }^{22}$

Caffery tentou obter um compromisso verbal de Vargas de que eliminaria as linhas do Eixo. Se, além disso, conseguisse convencê-lo a comprar a

18 BURDEN 14-8-1941.

19 HARDING 6-11-1941. What DSC has done and is prepared to do to bring about elimination of LATI. RG 84, v. XXXVIII.

20 HARDING 3-12-1941. RG 84, v. XXXVIII.

21 O'SHAUGHNENY 3-12-1941.LATI ceases operating between Recife and RJ . RG 84, v. XXXVIII.

22 CAFFERY 16-12-1941. RG 84, v. XXXVIII. 
Condor, estariam completamente confirmadas as "boas intenções brasileiras". ${ }^{23}$ A declaração de guerra ao Eixo por parte dos Estados Unidos fez circular comentários, dentre os quais o de que os Departamentos de Guerra e da Marinha estadunidenses, que vinham avaliando a frota transoceânica da Pan Am, se oporiam ao estabelecimento de qualquer serviço aéreo entre a América do Sul e o continente europeu, a despeito da disponibilidade de equipamento. ${ }^{24}$ Embora se soubesse que a rota Brasil-África, tal como sugerida pelo Departamento de Estado, não era um substituto equivalente à da LATI, ela reconhecidamente ofereceria inestimáveis vantagens políticas e de defesa para os Estados Unidos. Apesar de o acordo entre a RFC e a Pan Am ter sido concluído, sua assinatura dependia da esperada resposta de Vargas sobre a LATI. ${ }^{25}$ Enquanto isso, o Departamento de Estado mantinha a pressão sobre o Brasil, enfatizando seu sobressalto com as operações continentais da LATI e da Condor, e instruind o Caffery a enfatizar tais argumentos em uma reunião com Aranha. ${ }^{26} 0$ ponto era que ambas as empresas atuavam como centro de operações das linhas aéreas do Eixo remanescentes na América do Sul e estavam sendo usadas para propósitos de inteligência militar e naval. 0 principal senão era que a substituição total dos serviços efetuados pela LATI de transporte de correspondência e de passageiros brasileiros para os continentes europeu e africano continuava fora do alcance dos norte-americanos.

A entrada dos Estados Unidos na guerra teve reflexos políticos imediatos em território brasileiro. ${ }^{27}$ Quatro aviões italianos foram obrigados a manter-se estacionados no Recife, e tornaram-se tema de tensa negociação entre Caffery e o Ministro da Aeronáutica brasileiro. Enquanto o primeiro não pretendia liberá-los a retornar a Roma, o segundo resistia à idéia de prender suas tripulações, e declarava que não tinha interesse na compra dos equipamentos italianos. ${ }^{28}$ O embaixador italiano, Ugo Sola, acionou seus contatos políticos para conseguir que a LATI retomasse suas rotas intercontinentais, mas o Ministro da Aeronáutica, pressuroso, informou-lhe de que o governo estadunidense dizia-se disposto a atirar nos aviões da companhia italiana. Esta, no entanto, declarou-se disposta a enfrentar tal risco de "acidentes" para repatriar sua tripulação, junto com os aparelhos. No jogo de ameaças, o governo Mussolini assegurou que também "poderiam ocorrer alguns acidentes" com os aviões norte-americanos que trafegavam entre New York e a Europa (via Açores). ${ }^{29}$ A LATI tentou uma saída,

\footnotetext{
23 HARDING 10-11-1941. RG 84, v. XXXVIII.

24 HARDING 14-12-1941. Discussion of procedure to be followed in elimination the German influence in Condor. RG 84, V. XXXVIII.

25 DEPARTMENT Of STATE 13-1-1941. RG 84, v. XXXVIII.

26 DEPARTMENT Of STATE 17-12-1941. RG 84, v. XXXVIII.

27 Em 11 de dezembro de 1941, após o ataque a Pearl Harbor.

28 MILLER 29-1-1942. RG 84, v. XLVIII.

29 SOLA 13-1-1942. Embaixador da Itália a O. Aranha. RG 84, v. LI.
} 
oferecendo ao governo brasileiro a cessão de toda sua infra-estrutura no Brasil, e confiando a tripulações brasileiras o vôo entre o Brasil e a llha do Sol. Nova negociação sobre o retorno das aeronaves à Itália foi iniciada por Sola, que se referiu a um acordo entre as potências em guerra de que aviões comerciais não podiam ser presos. Aranha teria dado uma resposta evasiva. ${ }^{30} \mathrm{~A}$ embaixada norte-americana mantinha firmemente que a natureza da LATI era militar e não comercial. ${ }^{31}$

\section{Conclusão}

A LATI foi cerrada formalmente em 27 de dezembro de 1941, ${ }^{32}$ e um a um seus escritórios foram sendo desativados, no mesmo ritmo em que suas aeronaves, estacionadas por pilotos brasileiros, deixavam de funcionar. ${ }^{33}$ Não demorou para que o Departamento de Estado fosse pontualmente informado de que "todos os aviões pertencentes à LATI haviam sido definitivamente confiscados pelo governo brasileiro". ${ }^{34}$ Finalmente, Caffery pôde relatar que: "a nosso pedido, o governo brasileiro, por decreto-lei, cancelou os direitos de operação da LATI no Brasil". ${ }^{35} \mathrm{O}$ exército brasileiro requisitou os estoques remanescentes de gasolina de aviação que pertenciam às empresas do Eixo, e a Standard Oil foi autorizada a atendê-lo. ${ }^{36} \mathrm{O}$ equipamento da empresa italiana, posto à venda, tinha conseguido dois interessados: as próprias autoridades militares dos Estados Unidos e a subsidiária argentina da Fiat, que também era proprietária de uma linha aérea na Itália. ${ }^{37} \mathrm{O}$ Banco do Brasil rejeitou a oferta da Fiat, e o Ministro da Aeronáutica comprometeuse a requisitar as aeronaves para os norte-americanos após sua avaliação por uma comissão da FAB. Havendo acordo sobre o preço, a posse dos sete aviões que estavam em hangares no Rio de J aneiro, Recife e Natal seria legalizada. Hull e a DSC, que já contavam com uma avaliação de US\$ 400.000, feita por um de seus técnicos, enviado com essa finalidade, apressaram-se a agilizar as compras de equipamentos de vôo e negociar preços. A DSC propôs adquirir, por US\$300.000, motores, peças e aeronaves da LATI para usá-las como cargueiros. Mais tarde aumentou a oferta

30 CAFFERY 14-1-1942. In: U. S. Foreign Relations - The American Republics, 1942, Washington: Government Printing Office. v. V, p. 767.

31 CAFFERY 22-1-1942. RG 84, v. LI.

32 Ver as referências a uma carta forjada por encomenda do FBI e atribuída ao presidente da LATI na Itália, na qual Vargas é insultado e ridicularizado. Após conhecer seu conteúdo, o Presidente teria tomado a decisão de suspender os direitos de aterrissagem da LATI. http://homepages.nyu.edu/ th15/bradford.html e ABIN (2005). (THE ALGER HISS STORY. A history of forgery by typewriter. http://homepages.nyu.edu/ th15/bradford.html. Consultado em 28-9-2006)

33 SIMMONS 28-1-1942. Closure of offices of LATI Airline. RG 84, v. LI.

34 PETROGRANI 19-2-1942. RG 84, v. XLVIII.

35 CAFFERY 27-2-1943. Transmitting two strictly confidential reports concerning Embassy accomplishments. RG 84 . Strictly Confidential Files

36 12-3-1942.

37 CAFFERY 4-2-1942. In: U. S. Foreign Relations - The American Republics, 1942, Washington: Government Printing Office. v. V, p. 768. 
para US\$ 350.000 e a transação foi fechada. Uma das alegações era de que, se não fossem comprados, poderiam ser usados para finalidades contrárias aos interesses dos Estados Unidos. ${ }^{38}$ No contexto, 0 argumento ideológico podia ter mais peso do que o interesse puramente econômico, uma vez que o esforço de guerra podia ser esgrimido para justificar as mais variadas ações. Por fim, mesmo

em face de severa oposição dentro do governo brasileiro, a embaixada foi bemsucedida em negociar a compra, pela DSC, de todo o equipamento da LATI aqui. 0 preço pelo qual a embaixada obteve o equipamento foi consideravelmente menor do que a avaliação original feita pelos especialistas da DSC, e também do que o preço que o Brasil pediu inicialmente. Deve-se ter em mente, também, que o governo argentino, nessa conjuntura, está exercendo considerável pressão para obter esses aviões para uma linha aérea argentina que estava pronta para pagar muitas vezes a quantia pela qual nós conseguimos o equipamento..$^{39}$

Assim, essas agências estatais aproveitaram também para fazer mais um bom negócio com os despojos da LATI. A Fiat argentina acabou por comprar sete aviões, motores, peças e estações de rádio, ${ }^{40}$ e a Varig adquiriu um dos menores aparelhos da empresa. ${ }^{41} \mathrm{Um}$ conjunto de operações, amparadas na propaganda de uma causa e na superioridade técnica e econômica dos Estados Unidos, informava as negociações com setores civis e militares do governo brasileiro. Como resultado, o então "reticente" Vargas não apenas apoiou os Aliados como mais tarde enviou tropas à Europa. O fim do episódio LATI não representou a solução do problema, já que ainda restava a Condor, vinculada a capitais germânicos, mas foi um passo na direção de uma nova era, na qual a indústria aeronáutica norteamericana se tornaria dominante nos céus do Brasil.

\section{FONTES SECUNDÁRIAS COMPLEMENTARES:}

CASTELLANI, Antonio. Nascita e sviluppo dell'aviazione civile in Itália. http://www.aidaa.it/42004/civile.pdf. Consultado em 4-10-2006.

ABIN. Caso histórico. A carta forjada. Revista Brasileira de Inteligência. Brasília, v.1, n.1, dez. 2005, p. 91-6.

\footnotetext{
38 CLAYTON 8-5-1942. RG 84, v. LI.

39 CAFFERY 27-2-1943. Transmitting two strictly confidential reports concerning Embassy accomplishments. RG 84. Strictly Confidential Files.

40 30-1-1942.

41 CALLAMAN 19-3-1942. Recife. RG 84, v. XXXIII.
} 